\title{
Effect of Mobile Phase Variation and Purification on Chromatogram View by Using Fruits and Rose Extracts and HPLC Method
}

\author{
Gulten Cetin ${ }^{1}$, Fatma Turak ${ }^{1}$ \\ ${ }^{1}$ Yildiz Technical University, Faculty of Science and Art, Davutpaşa Campus, Department of Chemistry, Esenler, \\ Istanbul, Turkey \\ Correspondence: Gulten Cetin, Yildiz Technical University, Faculty of Science and Art, Davutpaşa Campus, \\ Department of Chemistry, 34220 Esenler, İstanbul, Turkey. Tel: (+90530)46666 42. E-mail: gultencetin1@hotmail.com
}

Received: May 13, 2016 Accepted: May 30, 2016 Online Published: June 12, 2016

doi:10.5539/ijc.v8n3p25 URL: http://dx.doi.org/10.5539/ijc.v8n3p25

\begin{abstract}
In this study extracts obtained from fruits of bluebery and cranberry and rose leaves were chromatografied by using mobile phase variation and DAD detector. The chromatograms were evaluated under different mobile phase systems such as isocratic and gradient elutions following purification procedure. The best separation conditions of pigments of anthocyanin in extracts and efficiency of purification procedure were searched by using mobile phases in the elution of isocratic and gradient modes. The chromatogram views have shown existence of anthocyanin constituents in the all fruits and rose extracts involving separation and qualitation. The effect of purification for separation and removal of pigments has been investigated.
\end{abstract}

Keywords: Blueberry, cranberry, HPLC, purification, rose extract

\section{Introduction}

Anthocyanins are derivatives of anthocyanidins and represent one of the most widely distributed classes of flavonoids in plants. They are responsible for blue, purple, violet,red and orange plant and fruit coloration (Jackman \& Smith, 1996). Anthocyanins are attractive materials as natural substitutes for synthetic pigments and antioxidants (Felgines et all., 2006). The natural sources of antioxidant compounds is necessary in food and pharmaceutical industries. Numerous studies have been carried out for chemical characterization of anthocyanins in various natural products. More than 540 naturally occuring anthocyanidin pigments in fruits and flowers have been identified (Anderson \& Francis, 2004), of which the most common is cyanidine, followed, in order of importance, by peonidin, delphinidin, pelargonidin, malvidin and petunidin ( Harborne \& Grayer, 1988 ; Hong \& Wrolstad, 1990). Gradient reversed phase HPLC with absorbance detection and MS analysis was used for identification of main anthocyanins in the fruit skin extracts of rose-myrtle (Liu, Guo \& Sun, 2012). The HPLC profile of elderberry pomace extract was obtained by enhanced solvent extraction and five different peaks of anthocyanins were identified such as 3-cyanidine, 3-sambubioside, 4-cyanidin, 3-glucoside, 5-quercetin glycoside, 6-rutin (Seabra, Braga, Batista \& Sousa, 2008). The HPLC separation of anthocyanins from grape by-products extract was represented with identification of peaks in the forms of monoglucoside; acetylglucoside and p-cournaroly glucoside by using a comparison of methods such as ultrasonics, high hydrostatic pressure or pulsed electric fields (Corrales, Toepfl, Butz, Knorr \& 2008). Anthocyanins were analysed by direct injection of the solutions according to the methods using LC-DAD/ ESI-MS technologies (Kammerer, Claus, Carle \& Schieber, 2004). The chromatographic separation of several anthocyanins in the extracts of skin of fresh red grapes was performed by linear gradient elution and different anthocyanins have been analyzed and identified on the basis of their retention times and UV-Visible spectra by comparison with standards isolated from grapes (Revilla, Ryan, Martin-Ortega, 1998). Under same conditions which are close to those described (Bakker \& Timberlake, 1985], acylated anthocyanins are stable. As the solvent systems generally used for extraction purposes are by no means spesific for anthocyanins frequently, the qualitative analysis of anthocyanins is complicated by the presence of other compounds that may interfere with the measurements (Markakis, 1974; Jackman, Yada \& Tung, 1987).

As considerable amounts of other compounds may also be extracted purification of extracts containing anthocyanin is often necessary. The different resins including ion exchange resins, polyamide powders and gel materials have been used to clean up or pre-fractionate of anthocyanins prior to isolation or characterization (Rodriguez-Saona \& Wrolstad, 2001).Column chromatography on Sephadex LH-20 has been used for purification of individual anthocyanins from crude extracts (Strack \& Wray, 1989). Baldi et al. proposed a complex fractionation method for grape by using an 
Extrelut 20 cartridge to remove lipophilic and polyphenolic compounds with hexane and ethylacetate followed by adsorption of the sample on to a C18 cartridge to eliminate hydrophilic molecules e.g. sugars and organic acids ( Baldi, Romani, Mulinacci, Vincieri \& Casetta, 1995).

This study describes a method for extraction, isolation and purification of anthocyanins from fruits of blueberry and cranberry and rose leaves. The procedure permits concentration of anthocyanin in the aqueous phase while removing lipids, chlorophylls and other water-insoluble compounds. The chromatogram views represent existence of qualitative pigment compositions by using mobil phase variation in the modes of isocratic and gradient elution techniques which were established by HPLC method. On the other hand, the chromatograms were evaluated comparatively as well as before and after purification. The efficiency of purification procedure was researched.

\subsection{Materials}

All reagents and solvents were purchased from Merck and were of analytical or high performance liquid chromatography grades. The fruits of blueberry, cranberry and leaf of rose plant were obtained from İstanbul, Turkey and they were used by cutting into the small pieces and stored in a plastic bag. They were kept at ambient temperature. Bidistilled water was used for the experiments. An ultrasonic bath was used to degase of mobile phase and samples before the analysis. HPLC analysis was conducted on an apparatus of Schmadzu series Prominence LC-20A with diode array detector. C18 column $(250 \times 4.6 \mathrm{~mm}$; particle size: $5 \mu \mathrm{m})$ was used for separations. C18 cartridges with C18 sorbent bonded on silica; ODS - 4-octadecyl silane $(20 \times 50 \mathrm{~mm})$ were used with single usable for purification of extracts.

\section{Methods}

\subsection{Extraction Procedure}

\subsubsection{Preparing of Extracts of Fruits and Rose Leaf}

The extraction from fresh skin of cranberry and blueberry and rose leaf was carried out in a water bath incubated an ambient temperature of $25^{\circ} \mathrm{C}$ held during $15 \mathrm{~min}$.

All extractions were conducted by a solid/liquid ratio of $0.020 \mathrm{~g} / \mathrm{mL}$ and $0.500 \mathrm{~g} / \mathrm{mL}$ and $0.125 \mathrm{~g} / \mathrm{mL}$ respectively for rose leaf, cranberry and blueberry where the solvent was a mixture of methanol and 0.1 M HCL solution 90:10 (v/v). Extraction procedures have been repeated three times in the same conditions for all materials. After each of the treatments the extracts were filtered and supernatants were collected for further analysis.

\subsubsection{Analyse of Anthocyanin by LC-DAD}

A high performance liquid chromatograph was used for analysis of the samples using an analytical C18 reverse phase column. The diode array detector was set to an acquisition range of $525 \mathrm{~nm}$. The samples were filtered through a 0.45 $\mu \mathrm{m}$ acrodics syringe filters (Millipore Corp., Bedford, MA). The separations were carried out with isocratic and gradient elutions. While time of harvest was $45 \mathrm{~min}$ for gradient programs isocratic programs had $40 \mathrm{~min}$ as running time.

The following elution modes were used.

\section{The mobile phase using a gradient program as follows:}

0-20 min, $5 \%$ A; $20-27 \min , 25 \%$ A; $27-45 \min , 5 \%$ A

Mobil phase: (A) Acetonitrile.

(B) \%1.5 Phosphoric Acid.

\section{The mobile phase using an isocratic program as follows:}

(A) \%1.5 Phosphoric Acid.

(B) $\% 1.5$ Phosphoric Acid.

$\% 20$ Acetic Acid.

$\% 25$ Acetonitrile.

The mobile phase has been used with isocratic mode by mixing the solutions of A and B in the ratio of 1:1.

Other chromatographic conditions were shown in Table 1. 
Table 1. The conditions for chromatographic analysis.

\begin{tabular}{|c|c|c|c|c|c|c|}
\hline Material & Mode & $\begin{array}{l}\text { Flow rate } \\
(\mathrm{mL} / \mathrm{min})\end{array}$ & $\begin{array}{c}\text { Injection } \\
\text { volume } \\
(\mu \mathrm{L})\end{array}$ & $\begin{array}{c}\text { Column } \\
\text { temperature } \\
\left({ }^{\circ} \mathrm{C}\right)\end{array}$ & $\begin{array}{l}\text { Wavelength } \\
\text { (nm) }\end{array}$ & $\begin{array}{c}\text { Running } \\
\text { time } \\
\text { (min) }\end{array}$ \\
\hline $\begin{array}{l}\text { Rose leaf } \\
\text { Cranberry } \\
\text { Blueberry }\end{array}$ & gradient & 0.7 & 40 & 45 & 525 & 45 \\
\hline $\begin{array}{l}\text { Rose leaf } \\
\text { Cranberry } \\
\text { Blueberry }\end{array}$ & isocratic & 1 & 20 & 45 & 525 & 40 \\
\hline
\end{tabular}

2.1.3 Purification Procedure

C18 cartridges have been used for fractionating of anthocyanins. The cartridge was conditioned by adding $4 \mathrm{~mL}$ of acidified water, followed by $4 \mathrm{~mL}$ of acidified methanol and $2 \mathrm{~mL}$ of acidified water to remove the remaining methanol. In an aqueous phase, anthocyanins are bound to the solid phase whereas polar compounds such as acids and sugars can be washed away with acidified water. Polyphenolic compounds are washed out by using ethyl acetate. Finally a relatively pure anthocyanin extract can be removed from the column with slightly acidified methanol. $0.1 \mathrm{M} \mathrm{HCI}$ aqueous solution/ methanol (10:90) was passed through a C 18 cartridge. $1 \mathrm{~mL}$ of the extract has been obtained by removing sugars and acids than anthocyanins.

\section{Results}

The following chromatograms obtained from extracts of rose leaf and fruits of cranberry and blueberry have been represented with reverse phase liquid chromatographic system by using different mobile phases and purification technique.

Figure 1 shows chromatograms registered at $525 \mathrm{~nm}$ corresponding to an extract obtained from rose leaf. 1a; isocratic elution mode, $1 \mathrm{~b}$; gradient elution mode, $1 \mathrm{c}$; gradient elution mode after purification.

Figure 2 shows chromatograms registered at $525 \mathrm{~nm}$ corresponding to an extract obtained from fresh skin of cranberry. $2 \mathrm{a}$; isocratic elution mode, $2 \mathrm{~b}$; gradient elution mode, $2 \mathrm{c}$; gradient elution mode after purification.

Figure 3 shows chromatograms registered at $525 \mathrm{~nm}$ corresponding to an extract obtained from fresh skin of blueberry. $3 \mathrm{a}$; isocratic elution mode, $3 \mathrm{~b}$; gradient elution mode, $3 \mathrm{c}$; gradient elution mode after purification.

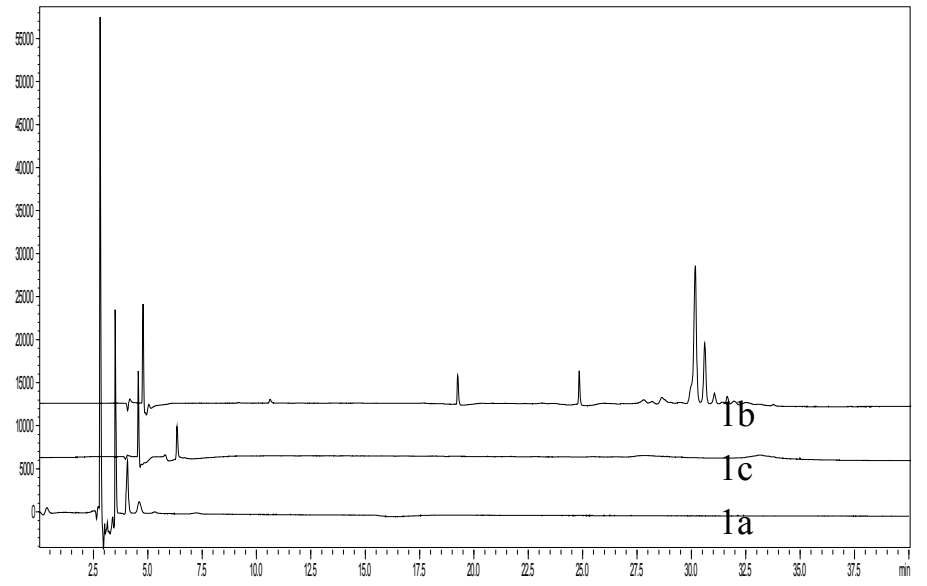

Figure 1. Chromatogram profile for rose leaf extracts at $525 \mathrm{~nm}$. 

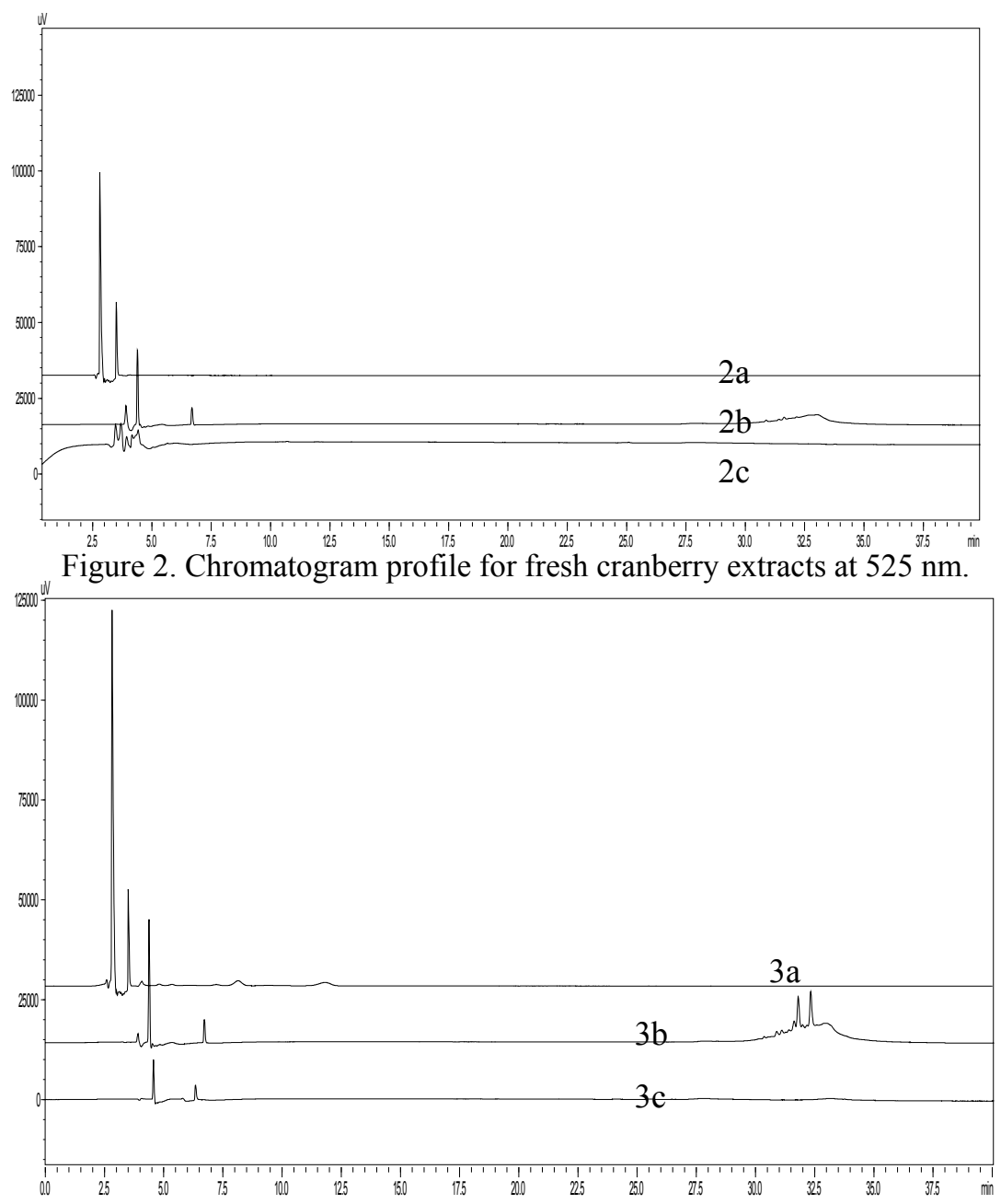

Figure 3. Chromatogram profile for fresh blueberry extracts at $525 \mathrm{~nm}$

\section{Discussion}

In this study the effects of usage of mobil phase were investigated comparatively in the modes of isocratic and gradient elution by using reverse phase liquid chromatographic method. The better separations have been observed by increasing number of peaks with higher retention times in the case of gradient mode. There is importance that passing of mobile phase from column in different constituents and time period and the mobil phase used in gradient mode is more apolar than isocratic phase. As the chromatograms have been evaluated a good separation of pigments in extracts with gradient elution has been occured by purification of extracts of blueberry, cranberry and rose leaf. The efficiency of purification on qualitative separation has been observed by examining respective chromatogram.

\section{Conclusion}

The fruits of bluberry and cranberry and plant of rose are source of anthocyanin to be used as coloration of food. The study describes a simple, fast and effective method for purification of anthocyanins using solid phase adsorption technique. The research could be important from an economic point of view because of composition of berries can be used for applications such as manufacture of minimally processed natural juices and jams. Purification will be useful as a source of anthocyanin colorants, helping to lower costs in the production of colorants to obtain a safe product with antioxidant potential. Also the applications of purified anthocyanins as natural $\mathrm{pH}$ indicator was studied (Bondre, Patil, Kulkarni \& Pillai, 2012). The application of purification procedure can be used effectively on separation of constituents in natural plant and fruit effluents. As pre-studies will be useful for characterization of anthocyanins in many natural fruits and plants these studies have been presented as a basic source for investigations.

\section{Acknowledgements}

This study is supported by Research Found of YILDIZ Technical University (Project Number: 2012-01-02 -KAP13).

\section{References}

Anderson, O., \& Francis, G. (2004). Techniques of pigment identification. Annual Plant Reviews- Plant Pigments and 
Their Manipulation, 14, 293-341.

Bakker, J., \& Timberlake, C. F. (1985). The distribution of anthocyanins in grape skin extracts of Port wine cultivars as determined by high performance liquid chromatography. Journal of the Sciences of Food and Agriculture 36, 1315-1324. http://dx.doi.org/10.1002/jsfa.2740361217

Baldi, A., Romani, A., Mulinacci, N., Vincieri, F. F., \& Casetta, B. (1995). HPLC/MS application to anthocyanins of Vitis vinifera L. Journal of Agricultural and Food Chemistry, 43, 2104-2109. http://dx.doi.org/10.1021/jf00056a027

Bondre, S., Patil, P., Kulkarni, A., \& Pillai, M. M. (2012). Study on isolation and purification of anthocyanins and its application as $\mathrm{pH}$ indicator", International journal of advanced biotechnology and research, 3(3), 698-702. ISSN0976-2612, online ISSN 2278-599x

Corrales, M., Toepfl, S., Butz, P., Knorr, D., \& Tauscher, B. (2008). Extraction of anthocyanins from grape by-products assisted by ultrasonics, high hydrostatic pressure or pulsed electric fields: A comparison. Innovative food science and emerging technologies, 9, 85-91.

Felgines, C., Talavera, S., Texier, O., Besson, C., Fogliano, V., Lamaison, J. L., La Fauci, L., Galvano, G., Remesy, C., \& Galvano, F. (2006). Absorption and metabolism of red orange juice anthocyanins in rats. Biritish Journal of Nutrition, 95, 898-904. http://dx.doi.org/10.1079/BJN20061728

Harborne, J. B., \& Grayer, R. J. (1988). The Anthocyanins, In: Harborne Although the Hemical Structure of Anthocyanins. The flavonoids: Advances in Research since 1980, Chapman and Hall (Eds.), (pp.1-20). London

Hong, V., \& Wrolstad, R. E. (1990). Use of HPLC separation / photodiode array detection for characterization of anthocyanins. Journal of Agricultural and Food Chemistry, 8(3), 708-715. http://dx.doi.org/10.1021/jf00093a026

Jackman, R. L., \& Smith, J. L. (1996). Anthocyanins and Betalains. In Natural Food Colorants (2nd ed.) G. A. F. Hendry \& J. D. Houghton (Eds.), (pp.244-309), Blackie and Son, Ltd., London.

Jackman, R. L., Yada, R. Y., \& Tung, M. A. (1987). A Review: Separation and chemical properties of anthocyanins used for their qualitative and quantitative analysis. Journal of Food Biochemistry, 11, 279-308. http://dx.doi.org/10.1111/j.1745-4514.1987.tb00128.x

Kammerer, D., Claus, A., Carle, R., \& Schieber, A. (2004). Polyphenol screening pf pomace from red and white grape varieties by HPLC-DAD-MS/MS. Journal of agricultural and food chemistry, 52(12), 4360-4367. http://dx.doi.org/10.1021/jf049613b

Liu, G. L., Guo, H. H., \& Sun, Y. M. (2012). Optimization of the extraction of anthocyanins from the fruit skin of Rhodomyrtus tomentosa Hassk and Identification of anthocyanins in the extract using high performance liquid chromatography-electrospray ionization-mass spectrometry. International Journal of Molecular Sciences, 13, 6292-6302. http://dx.doi.org/10.3390/ijms13056292

Markakis, P. (1974). Anthocyanins and their stability in foods. CRC Crit. Rev. Food Technol., 4, 437-456. http://dx.doi.org/10.1080/10408397409527165

Revilla, E., Ryan, J. M., \& Martin-Ortega, G. (1998). Comparison of several procedures used for the extraction of anthocyanins from red grapes. Journal of Agricultural and Food chemistry. 46, 4592-4597. http://dx.doi.org/10.1021/j99804692

Rodriguez-Saona, L. E., \& Wrolstad R. E. (2001). Extraction, isolation and purification of anthocyanins. Current Protocols in Food Analytical Chemistry, F1.1.1-F1.1.11, 2001. Copyright@2001 by John Wiley \& Sons, Inc. http://dx.doi.org/10.1002/0471142913.faf0101s00

Seabra, I. J., Braga, M. E. M., Batista, M. T. P., \& Sousa, H. C. (2010). Fractioned high pressure extraction of anthocyanins from elderberry pomace. Food and Bioprocess Technology, 3(5), 674-683. http://dx.doi.org/10.1007/s11947-008-013

Strack, D., \& Wray, V. (1989). Anthocyanins. In methods in plant biochemistry, vol. 1: Plant phenolics, Dey, P.M. and Harborne, J.B, eds., pp. 325-359. Academic Press, San Diego, California.

\section{Copyrights}

Copyright for this article is retained by the author(s), with first publication rights granted to the journal.

This is an open-access article distributed under the terms and conditions of the Creative Commons Attribution license (http://creativecommons.org/licenses/by/4.0/). 